\title{
La maternidad y las relaciones materno-filiales en la obra de Elena Ferrante
}

\section{Motherhood and Mother-Child Relationships in Elena Ferrante's Work}

\section{Resumen}

Bajo el pseudónimo de Elena Ferrante, la escritora italiana de identidad desconocida hasta la fecha recrea un universo literario femenino en el que los vínculos entre mujeres son la clave para desarrollar historias de desestabilización personal y superación. Por su enfoque novedoso, llama la atención la relación conflictiva que se plantea entre mujeres o entre madre e hija, como en la novela I giorni dell'abbandono. Por ello, en el presente trabajo se analizará la representación de la maternidad en la literatura y, de manera especial, nos centraremos en el tratamiento de la maternidad y las relaciones materno-filiales en la mencionada obra.

Palabras clave: maternidad, Elena Ferrante, reflejo materno, subjetividad.

\begin{abstract}
Under the pseudonym Elena Ferrante, the Italian writer of unknown identity thus far evokes a female literary universe in which the links between women are pivotal to unfold stories of personal destabilization and self-improvement. Due to its novel touch, the stormy relationship depicted between mother and daughter in novels such as I giorni dell'abbandono really attracts the attention. Based on the foregoing, in the present work, the representation of maternity in literature, and especially, the appraisal of maternity and mother-child relationships in the works of Ferrante will be analyzed.
\end{abstract}

Keywords: Motherhood, Elena Ferrante, Maternal Reflex, Subjectivity.

\section{SUMARIO}

1.- Las relaciones entre la maternidad y la literatura. 2.- La representación de la maternidad en la literatura femenina italiana del siglo XX. 3.- Introducción a la obra de Elena Ferrante. 3.1.-La historia de Olga, una historia de desestructuración; 3.2.- Olga e Ilaria: la maternidad negada; 3.3. Olga y los fantasmas de la «madre»; 4. Conclusión. -Referencias y Bibliografía.

1 Departamento de Filología Francesa, Románica, Italiana y Árabe. Área de italiano. Universidad de Murcia. Maria.reyes1@um.es 


\section{Las relaciones entre la maternidad y la literatura}

Cuando se abordan las relaciones que se establecen entre la maternidad y la tradición literaria, eminentemente masculina ${ }^{2}$, es posible afirmar que existe un desequilibrio evidente entre la representación de la madre, un rol que se suele dar por descontado en las producciones literarias por actuar como un agente pasivo, y del padre que, según Fabiano Massimi (2012), generalmente juega un papel decisivo en la narración y desplaza a la mujer al segundo plano. La maternidad ha tenido siempre una gran trascendencia en la vida de la mujer y, como Lucy Delogu sostiene, sus efectos han sido «a volte devastanti nella vita della donna, ed è stata soprattutto sfruttata come vincolo biologico per imprigionarla» (Delogu, 2015: 7) ${ }^{3}$ y relegarla a los márgenes sociales. Además, no solo queda desplazada la figura de la madre sino también el fenómeno de la maternidad en su totalidad: «la maternidad, y en particular la concepción, el embarazo, el parto, el puerperio y la crianza de los hijos cuando son aún muy pequeños, han carecido, al menos hasta las últimas décadas, de atención literaria» (Herrero Gil, 2014).

La manera en la que se representa la madre y la escasa visibilidad de la experiencia maternal en la literaria tradicional ha dado lugar a varias hipótesis, y todas ellas están relacionadas con los parámetros masculinos que se han utilizado para conceptualizar la realidad. El imaginario cultural patriarcal contempla dos modelos de madres posibles: la imagen positiva de la madre, que aparece representada simbólicamente como la cuidadora incondicional del hogar, la heroína doméstica, cuya capacidad de intervención es limitada en un espacio que, paragonado al espacio en el que se mueve el padre, se reduce a cuatro paredes donde la vida trascurre aparentemente con mínimas disrupciones. Su experiencia en el mundo aparece ligada a los valores predominantes masculinos y, en consecuencia, la mujer-madre ${ }^{4}$, actúa para cumplir dos funciones determinadas: ser reproductora de hijos y transmisora de la ideología dominante. Por otro lado, y respecto al segundo modelo, la literatura ofrece una imagen opuesta a la anterior, la madre incapaz, la desertora o la madrastra, que rompen con el rol materno tradicional y alimentan un desencuentro entre la figura de la madre y de la mujer.

Ambos estereotipos femeninos, sobre todo presentes en el género novelesco a partir del siglo XVII, se originaron en los inicios de las distintas culturas occidentales cristianas con las imágenes de María y Eva:

The holy Virgin, pure and good, willing to sacrifice and to be made an instrument of God versus the temptress, herself seduced by the Devil, carnal in

2 Las obras comprendidas dentro de esa tradición literaria han seguido un canon masculino que Enric Sullà define como un «baluarte [...] de la cultura masculina blanca occidental» (Sullà, 1998: 187).

3 Las traducciones de las citas son propias: «[...] a veces devastadores en la vida de una mujer, y sobre todo ha sido explotada como vínculo biológico para encarcelarla».

4 La estudiosa América Luna Martínez, en su trabajo acerca de las relaciones entre maternidad y literatura, se detiene en la relevancia de la representación de las madres en la literatura y afirma que su estudio es «fundamental si consideramos que por varios miles de años uno de los rasgos de la identidad femenina ha sido dado en función de su capacidad reproductora, es decir para el patriarcado mujer es sinónimo de madre» (2001: 37). 
her sinfulness, who defies the rules lain down to her and thereby causes not just her own fall but the fall of man, the expulsion from Paradise. These two biblical women represent a kind of female duality, the two core qualities that have traditionally been assigned to women (Kühl, 2016: 171- 172) .

Estas dos imágenes, modificadas y adaptadas a cada tiempo y lugar, han servido para asentar las bases de la feminidad dentro de una cultura masculina. Sin embargo, a lo largo del siglo $\mathrm{XX}$, es posible apreciar un cambio en la imagen que se proyecta de la madre en la literatura, que desde ese momento aparece en numerosas ocasiones como el personaje principal, y la relevancia que adquiere la cuestión de la maternidad, un argumento que también aborda la dimensión de las relaciones materno-filiales. Estos cambios están motivados prevalentemente por el auge de las escritoras y el movimiento feminista, dos factores que impulsan un acercamiento a la lectura como mujer y como feminista, y que subvierten «la construcción de un pensamiento patriarcal que ha formado una conciencia sobre lo femenino desde su particular perspectiva» (Peppino Barale, 2012: 116).

Para desafiar las estructuras de pensamiento propuestas por la cultura patriarcal, Anna Rossi Doria (1993) considera fundamental construir una tradición para la creación de una existencia autónoma de las mujeres. Para elaborar dicha tradición en el campo literario, la estudiosa Neria de Giovanni (2003) apunta a la concienciación de la autoría femenina ${ }^{6}$ en un proceso que denomina maternage, y que consiste en reconocer la tradición anterior para elaborar una reflexión teórica que sirva de modelo para las generaciones sucesivas. Es necesario que las mujeres observen, analicen y reconozcan a las escritoras anteriores y sus experiencias para reconstruir una genealogía femenina:

... una storia di soggetti femminili, diversi tra loro, che oggi serve per dare sfondo e peso alle conquiste e ai problemi di oggi, serve a dare il senso della storia alle donne che non sanno di possederla e che, finché non la conosceranno, avranno maggiore difficoltà a essere autonome, magari anche da essa, per costruire la propria soggettività (Santoro, 1997: 13) .

5 «La santa Virgen, pura y bondadosa, dispuesta a sacrificarse y a convertirse en un instrumento de Dios contra la tentadora, seducida por el Diablo, carnal en su pecaminosidad, que desafía las normas que se le imponen y de este modo causa no solo su propia caída sino la caída de los hombres, la expulsión del Paraíso. Estas dos mujeres bíblicas representan un tipo de dualidad femenina, englobando las dos cualidades principales que se le han asignado a las mujeres tradicionalmente».

6 La estudiosa señala que una de las causas que ha obstaculizado el asentamiento de la autoría femenina en la literatura es que las mujeres han sido las primeras «[...] a non portare consapevolezza, non avere coscienza della propria opera» «que no han propiciado la toma de conciencia, que no han tenido conciencia de la propia obra» (De Giovanni, 2003: 9).

7 «... una historia de sujetos femeninos, distintos entre ellos, que hoy sirve para dar un trasfondo y un peso a las conquistas y a los problemas de hoy, sirve para dar sentido a la historia de las mujeres que no saben que la poseen y que, hasta que no la conozcan, tendrán mayores dificultades para ser autónomas, y posiblemente a raíz de esta, podrán construir la propia subjetividad». 
No urge solo reconocer y afirmar una tradición anterior, sino también transformar la literatura, utilizar un lenguaje renovado ${ }^{8}$ y adaptarla a las necesidades de las escritoras que, por su experiencia en el mundo, será diversa a la del varón. Se crea así una nueva escritura, la femenina, que plantea temáticas concernientes a las realidades de las mujeres, como es la maternidad, y crean una crítica al respecto.

\section{La representación de la maternidad en la literatura femenina italiana del siglo XX}

Muchas pensadoras feministas se han detenido en el análisis de la disciplina literaria ya que esta puede ser entendida como una fuente de acceso al conocimiento y una forma de indagar en nuestra experiencia en el mundo real o imaginario:

El valor de lo literario para la vida humana tiene que ver con su capacidad para modelar nuestra experiencia, para atribuir al universo una imagen sin la cual no podríamos captarlo, que regula y dirige nuestros códigos de comunicación. [...]. Desde este punto de vista, la literatura es ordenación, interpretación y articulación de la experiencia (Moreno, 1997: 108).

La crítica literaria feminista comienza a indagar y replantea el problema de la carencia de referentes literarios que interpretaran y articularan la experiencia femenina narrada por mujeres como sujetos, sin caer en los estereotipos masculinos dominantes. A lo largo del siglo XX, en Italia, gracias a las aportaciones del movimiento feminista ${ }^{9}$, las mujeres utilizan la escritura para dar voz a sus propias exigencias y se acercan a los textos de escritoras del pasado desde una óptica diversa, redescubriendo escritos privados de autoría femenina tales como cartas, diarios o autobiografías, logrando así dar visibilidad a la contribución escritural de muchas mujeres «presentada como prueba de la conciencia de las mujeres y de su expresión» (Peppino Barale, 2012: 117). Por lo tanto, y como propone Marina Zancan (1998), la escritura femenina recorre un doble itinerario en el que se hace necesario visibilizar a las escritoras y reconsiderar el aparato crítico de sus textos, que se manifiesta a través de un imaginario propio:

8 Chiara Stinghi hace referencia a la especificidad del lenguaje de las mujeres debido a las diferencias biológicas, sociales e históricas que han configurado la existencia femenina: «La scrittrice prova ad esprimere sensazioni fisiche legando la scrittura al corpo che entra nel linguaggio delle donne non solo come tema, ma anche come percezione: la lingua utilizzata non si limita ad esprimere idee, ma evoca gesti, emozioni, il linguaggio stesso della fisicità. Le donne parlano di emozioni e di sentimenti attraverso il linguaggio del corpo: l'arrossire, il comparire di un sorriso sono la corrispondenza tra il dentro ed fuori, tra emozioni e apparenza» «La escritora intenta expresar sensaciones físicas vinculando la escritura al cuerpo que forma parte del lenguaje de las mujeres no solo como tema, sino también como percepción: la lengua utilizada no se limita a expresar ideas, también evoca gestos, emociones, el lenguaje propio de la experiencia física. Las mujeres hablan de emociones y sentimientos a través del lenguaje del cuerpo: el hecho de ruborizarse, de que aparezca una sonrisa son la correspondencia entre el dentro y el fuera, entre emociones y apariencia» (Stinghi, 2005).

9 Con el «movimiento feminista» pretendemos abarcar no solo la década de los 70 sino también los origines del movimiento en Italia en la segunda mitad del siglo XIX con personalidades tan relevantes para el devenir de las mujeres como Anna Maria Mozzoni, Cristina Trivulzio Belgiojoso o Anna Kuliscioff. 
Leggere le scritture delle donne significa recuperare non solo testi e nomi cancellati dalla nostra memoria, ma, se la lettura è quella "giusta», recuperare la funzione culturale, oltre che sociale, che le donne svolsero in Italia, e capire meglio la Storia, quanto essa sia ricca, articolata, come la vita, e quante possibilità di scelta e di sguardo essa offra ogni giorno (Santoro, 1997: 19) ${ }^{10}$.

La representación de la maternidad en el contexto literario italiano pone de manifiesto, como apunta Giovanna Miceli Jeffries (1997), la trascendencia que esta tiene y ha tenido en el desarrollo político, social y cultural del país así como la evolución del rol de la madre. Si nos detenemos en el siglo XX, la maternidad ha sido objeto de una constante negociación por parte de ideologías dominantes, como el Catolicismo o el Fascismo, y las revisiones que proponen las feministas del estatus de la maternidad:

While Catholicism and Fascism concurred to institutionalized motherhood as the only and supreme goal of womanhood -with the subsequent establishment of the stereotyped Italian «mamma» in popular as well as ethnic culture- the women's liberation and emancipatory movement in the early seventies critiqued and destabilized that image by reclaiming women's control of their bodies, as well as political, private, and economic quality (Miceli Jeffries, 1997: 212) ${ }^{11}$.

En estos años las mujeres tratan de recuperar la genealogía madre-hija, alejándose de la imagen materna que se ha transmitido y que «emerge continuamente come un'ombra minacciosa anche nelle cronache del presente» (Chemotti, 2009: $21)^{12}$. Al inicio del siglo, escritoras italianas como Grazia Deledda, Annie Vivanti o Ada Negri mostraron su rechazo ante los nuevos ideales católicos que pretendían mantener la unidad familiar bajo el cuidado materno. Sibilla Aleramo revolucionó el panorama literario con su ensayo Una donna en el que cuestiona varios aspectos de la vida de la mujer, entre ellos el rol de la madre, y afirma que: «... la buona madre non debe essere, come la mia, una semplice creatura di sacrificio: debe essere una donna, una persona umana» (Aleramo, [1906] 2011: 85) ${ }^{13}$. La imagen de la madre esclava, para Aleramo, se convierte en el fatal e inevitable destino de las hijas, un sino que define como una monstruosa cadena de servidumbre, de mortificación y negación. La escritora y periodista Matilde Serao se opone abiertamente a

10 «Leer las escrituras de las mujeres significa recuperar no solo textos y nombres cancelados de nuestra memoria, sino que, si la lectura es la «justa», [significa] recuperar la función cultural, además de social, que las mujeres desarrollaron en Italia, y comprender mejor la Historia, cuanto sea rica, articulada, como la vida, y cuantas posibilidades de elección y perspectivas ofrece cada día» .

11 «Mientras que el Catolicismo y el Fascismo coinciden en institucionalizar la maternidad como el único y supremo objetivo de las mujeres -con la consiguiente creación de la estereotipada «mamma» italiana en la cultura étnica y popular- la liberación de las mujeres y el movimiento emancipador de los inicios de los setenta criticó y desestabilizó esa imagen reivindicando el control de las mujeres sobre su cuerpo, así como sus atributos políticos, privados y económicos».

12 «emerge continuamente como una sombra amenazadora en las crónicas del presente».

13 «... la buena madre no tiene que ser, como la mía, una simple criatura de sacrificio: debe ser una mujer, una persona humana». 
la exaltación de la figura maternal propuesta por el régimen fascista y dirige varios artículos publicados en $\mathrm{Il}$ Giorno a todas las madres italianas que experimentan el dolor por la pérdida de los hijos en la guerra. Otra escritora contraria a las ideas fascistas fue también Alba de Céspedes que, como Laura Benedetti sostiene, hace un retrato de la mujer real y de un personaje que resulta «a total stranger in the culture of motherhood promoted by Fascism» (Benedetti, 2007: 69) ${ }^{14}$.

Tras la Segunda Guerra Mundial, y siguiendo el estudio de Benedetti (2007), surgen nuevas figuras literarias que se enfrentan a un sentimiento identitario dividido entre la mujer y la madre, como proponen las escritoras Natalia Ginzburg o Fausta Cialante. Desde una perspectiva diversa, Elsa Morante realza la figura de la madre ${ }^{15}$ y las relaciones materno-filiales ocupan un papel central en su obra, destacando especialmente la relación casi mística entre Ida y su hijo Useppe ${ }^{16}$ en la novela La Storia (1974). Otra de las escritoras que explora las relaciones entre la madre y el hijo es Grazia Livi, que describe la relación con el hijo en un modo físico y sensual (Blelloch, 1987) en la novela L'amore (1978). Lalla Romano da una visión personal de las relaciones materno-filiales, profundas y apasionadas, que califica como un fracaso por el desequilibrio de poder: «Lalla Romano affida alle sue pagine una denuncia forte e coraggiosa e ci consegna l'immagine tenace e sofferta di una donna- madre e di una scrittrice attenta e sensibile, tra pietas e amarezza [...]» (Chemotti, 2009: 170) ${ }^{17}$.

El argumento de la maternidad y las relaciones materno-filiales continúa suscitando interés entre las escritoras italianas contemporáneas, como Clara Sereni, Nadia Comencini, Adriana Assini o Francesca Sanvitale, quienes reflejan en sus obras distintas visiones de la maternidad y una multitud de posibles relaciones entre madres e hijos. Una de las escritoras que visibiliza la maternidad desde la subjetividad femenina y explora las relaciones y los conflictos que surgen de las relaciones materno-filiales es Elena Ferrante, una enigmática escritora que ha revolucionado el panorama literario actual más allá de las fronteras italianas.

\section{Introducción a la obra de Elena Ferrante}

Elena Ferrante, o «Elena Ferrante», es una de las escritoras italianas más relevantes de los últimos años. Su anonimato, el pseudónimo tras el que se esconde y su peculiar forma de conceder entrevistas, todas por escrito, ha creado un gran revuelo en los círculos literarios y mediáticos. El concepto que Ferrante tiene de la obra literaria y del escritor, a quien considera que se le otorga una excesiva aten-

14 «un extraño total en la cultura de la maternidad promovida por el Fascismo».

15 La maternidad para Elsa Morante es «uno dei momenti più arcani e divini del grande enigma della natura» «uno de los momentos más arcanos y divinos del gran enigma de la naturaleza» (Sgorlon, 1988: 104).

16 El personaje de Ida fue criticado por las feministas que acusaban a Morante de representar «una donna idiota, opressa e incapace di ribellarsi» «una mujer idiota, oprimida e incapaz de rebelarse» (Blelloch, 1987: 89).

17 «Lalla Romano delega en sus páginas una denuncia fuerte y valiente y nos muestra la imagen tenaz y sufriente de una mujer-madre y de una escritora atenta y sensible, entre la pietas y la amargura [...]» 
ción, ha suscitado un considerable interés por parte de la crítica al cuestionar las reglas del mercado editorial actual. Sorprende su persistente negativa a participar en todo tipo de actividad promocional y opta por dejar que el libro recorra su trayectoria y sea valorado únicamente por la excelencia del contenido que, generalmente, se centra en distintos aspectos del universo femenino.

La scrittrice predilige l'assenza perché consegna il presente solo alle sue parole e in esse è viva in maniera lancinante, acuta e forte. Perché, come la Napoli in cui ambienta i suoi romanzi, Elena Ferrante non crede al culto dell'effigie, assume la fisicità dei suoi libri, veri noir alla ricerca delle ombre dentro un viaggio che scende agli inferi del caos e dei nemici originari: la sua scrittura, elegante, sensuale e raffinata, scava nelle pieghe dell'animo femminile [...] (Chemotti, 2009: 272) ${ }^{18}$.

Ferrante utiliza la escritura para explorar diversos aspectos de la experiencia femenina e indaga en la naturaleza de las relaciones de amistad, familiares o conyugales que las mujeres mantienen con su entorno. Estas relaciones, generalmente conflictivas, conducen a una serie de reflexiones formuladas a través de los pensamientos de los personajes, quienes analizan sus problemas existenciales e identitarios, y tratan de reconducir sus vidas. La existencia de estas mujeres está estrechamente vinculada a un profundo malestar y al inconformismo de una vida construida en torno a las estructuras patriarcales. Cuando, por diversos motivos, comienzan a desestructurarse sus pilares existenciales, los personajes femeninos sufren fuertes desequilibrios emocionales e inician una andadura hacia su reconstrucción personal, cuestionando los roles femeninos y los diferentes vínculos que se crean entre las mujeres. Como Ferrante argumenta, sus protagonistas experimentan un proceso de fragmentación para, más tarde, reconstruir su identidad quebrantada en un proceso que explica como:

... raccontare, oggi, un io femminile che all'improvviso si percepisce in destrutturazione, smarrisce il tempo, non si sente più in ordine, si avverte come un vortice di detriti, un turbino di pensieri-parole. Per poi fermarsi bruscamente e ricominciare da un nuovo equilibrio, che non è necessariamente più avanzato del precedente e nemmeno più stabile (La Frantumaglia, 2003: 215) $)^{19}$

Autora de la tetralogía de L'amica geniale, título con el que se da comienzo a la historia de amistad entre Lina y Lenù, Ferrante ha publicado, además, L'amore molesto (1992), I giorni dell'abbandono (2002) y La figlia oscura (2006), siete novelas en las que se

18 «La escritora prefiere la ausencia porque entrega al presente solo sus palabras y en estas está viva de manera lancinante, aguda y fuerte. Porque, como la Nápoles en la que ambienta sus novelas, Elena Ferrante no cree en el culto de la efigie, asume la materialidad de sus libros, auténticos noir en busca de las sombras dentro de un viaje que desciende a los infiernos del caos y de los enemigos originarios: su escritura, elegante, sensual y refinada, ahonda en los pliegues del alma femenina».

19 «... narrar, hoy, un yo femenino que de repente se percibe en plena desestructuración, pierde la noción del tiempo, no se siente en orden, se observa como una vorágine de detrito, una turbina de pensamientos-palabras. Para después afirmarse bruscamente y volver a empezar desde un nuevo equilibrio, que no es necesariamente más avanzado que el anterior ni tampoco más estable». 
proponen diferentes dimensiones de las posibles relaciones que se establecen entre mujeres: madre-hija, amigas, mujer-mujer, mujer-espejo. A continuación, pasaremos a analizar la figura de la madre y las relaciones materno-filiales en la obra I giorni dell'abbandono.

\subsection{La historia de Olga, una historia de desestructuración}

Los personajes femeninos de la narrativa de Ferrante, y en este caso Olga, la protagonista de I giorni dell'abbandono (GA, de aquí en adelante), comparten la necesidad de analizar su reflejo en otras personas, en ellas mismas o en objetos, que serán cruciales para rastrear en su pasado y poder hallar fragmentos dispersos de la propia identidad que les guíen hacía una posición más estable en el presente. Sin embargo, la imagen especular que las mujeres observan de ellas mismas no será siempre satisfactoria o cumplirá las expectativas deseadas por el sujeto. En ocasiones, el reflejo que obtienen tras una mirada detenida en otras mujeres puede ser un elemento tranquilizador por el hecho de revelar una imagen conocida, pero también puede traicionar la propia imagen y desestabilizar al sujeto: «Gli specchi riflettono le immagini, ma nascondono le forme che riflettono, le lasciano avvolte nel mistero, e ci rimandano immagini allo stesso tempo familiari ed estranee, simulacri di qualcosa che ci assomiglia ma che allo stesso tempo non coincide perfettamente con noi» (Conti, 2015: 104) ${ }^{20}$. El simulacro de la imagen frente al espejo podría entenderse como la proyección de la imago, es decir, el reflejo de la representación inconsciente del sujeto, como sostenía Carl Gustav Jung (1912) ${ }^{21}$.

En las novelas de Elena Ferrante, la imago aparece como la identificación del sujeto con la imagen del otro, donde el otro es generalmente una construcción estereotipada de la mujer, creada para complacer a un modelo de sociedad patriarcal. Cuando los parámetros de la realidad en la que viven son vapuleados, las mujeres toman conciencia sobre el desequilibrio existente entre su imagen e imago y, en consecuencia, sobre su propia existencia. El trastorno de la imagen femenina, ocasionado por diversos motivos, ha sido conceptualizado por la propia escritora con un término que ha denominado frantumaglia ${ }^{22}$ :

La frantumaglia è il deposito del tempo senza l'ordine di una storia, di un

20 «Los espejos reflejan las imágenes, pero esconden las formas que reflejan, las dejan envueltas en el misterio y, al mismo tiempo, nos remiten a imágenes familiares y extrañas, simulacros de figuras que se nos asemejan y, sin embargo, no coinciden perfectamente con nosotros».

21 El término imago se define como el «prototipo inconsciente de personajes que orienta electivamente la forma en que el sujeto aprehende de los demás; se elabora a partir de las primeras relaciones inter-subjetivas reales y fantásmicas con el ambiente familiar» (Ávila Espada, Rojí Menchaca, Saúl Gutierrez, 2014: 643).

22 En el homónimo libro (de aquí en adelante $L F$ ), publicado en el 2003, Ferrante hace alusión al origen del término, pronunciado por su madre cuando la escritora era pequeña y que, años más tarde, ha conseguido reconceptualizar. «Mia madre mi ha lasciato un vocabolo del suo dialetto che usava per dire come si sentiva quando era tirata di qua e di là da impressioni contraddittorie che la laceravano. Diceva che aveva dentro una frantumaglia. La frantumaglia (lei pronunciava frantummáglia) la deprimeva. [...] Era una parola per un malessere non altrimenti definibile, rimandava a una folla di cose eterogenee nella testa, detriti su un'acqua limacciosa del cervello. La frantumaglia era misteriosa, causava atti misteriosi, era all'origine di tutte le sofferenze non riconducibili a una sola evidentissima ragione» «Mi madre me ha dejado un vocablo de su dialecto que usaba para decir cómo se sentía cuando se dejaba llevar por impresiones contradictorias que la afligían. Decía que tenía dentro una frantumaglia. La frantumaglia (ella pronunciaba frantummáglia) la deprimía [...] Era una palabra para un malestar que no podía ser definido de otra manera, aludía a una cantidad de cosas heterogéneas en la cabeza, detritos sobre un agua fangosa del cerebro. La frantumaglia era misteriosa, causaba actos misteriosos, estaba en el orgien de todos los sufrimientos no atribuibles a una sola razón evidente» (LF, 2003: 109). 
racconto. La frantumaglia è l'effetto del senso di perdita, quando si ha la certeza che tutto ciò che ci sembra stabile, duraturo, un ancoraggio per la nostra vita, andrà a unirsi presto a quel paesaggio di detriti che ci pare di vedere. La frantumaglia è percepire con dolorosissima angoscia da quale folla di eterogenei leviamo, vivendo, la nostra voce e in quale folla di eterogenei essa è destinata a perdersi $(L F, 2003$ : $109)^{23 .}$

En el caso de Olga, la desestabilización del sujeto surge tras la fragmentación de su vida anterior, su matrimonio, y el hecho de ser abandonada por el marido que, a su vez, se enamora de Carla, una mujer más joven. La desestructuración de los principios culturales y sociales, el final de un amor o de la vida en pareja, abre paso al abismo de la frantumaglia. La escritora defiende que su novela no ahonda en el fatídico hecho conyugal que experimenta Olga sino en la fragmentación y la consiguiente recomposición del sujeto que, en definitiva, narra una «historia de desestructuración» como la escritora sugiere:

In realtà Olga è donna d'oggi che sa di non dover reagire all'abbandono spezzandosi. Nella vita come nella scrittura mi interessa l'effetto di questo sapere nuovo: come agisce, che resistenza oppone, come combatte contro la voglia di morte e si conquista il tempo necessario per imparare a sopportare il dolore, quali stratagemmi o finzioni mette in atto per riaccettare la vita $(L F, 2003: 88)^{24}$.

La protagonista narra el sufrimiento causado por el abandono y la traición de Mario, su marido, y cómo la ausencia de este en el hogar descompondrá su identidad, viéndose forzada a arrastrar como un peso insoportable su existencia y su condición de mujer y de madre. La integridad física y moral de Olga se irá fragmentando poco a poco y se manifestará a través del agotamiento emocional y corporal. La protagonista caerá en el abismo que se abre paso tras el abandono y sentirá su fracaso personal en los varios aspectos de su vida, como mujer, madre o esposa. A continuación se examinará la figura materna de Olga y la relación que mantiene con sus hijos, especialmente con Ilaria, que estará marcada por una creciente hostilidad tras el abandono.

\subsection{Olga e Ilaria: la maternidad negada}

En el campo del psicoanálisis, la imagen de la madre es el primer espejo en el que el neonato se mira y, en un primer momento, se identifica. No obstante, en un

23 «La frantumaglia es el depósito del tiempo sin el orden de una historia, de una narración. La frantumaglia es el efecto del sentido de la pérdida, cuando se tiene la certeza de que todo aquello que parecía estable, duradero, un ancla para nuestra vida, formará parte pronto de un paisaje de detritos que nos parece ver. La frantumaglia es percibir con dolorosísima angustia desde qué multitud heterogénea elevamos, viviendo, nuestra voz y en qué multitud heterogénea esta está destinada a perderse».

24 «En realidad Olga es una mujer de hoy que sabe que no tiene que reaccionar al abandono rompiéndose. En la vida como en la escritura me interesa el efecto de este nuevo saber: cómo reacciona, qué resistencia pone, cómo combate las ganas de morir y conquista el tiempo necesario para aprender a soportar el dolor, qué estrategias o ficciones utiliza para volver a aceptar la vida».

ASPARKÍA, 31; 2017, 47-63 - ISSN: 1132-8231 - DOI: HTTP:/ / DX.DOI.ORG/10.6035/AsPARKIA.2017.31.3 
estado posterior de la vida, el espejo materno no sirve para la identificación del sujeto con la madre, sino para iniciar un proceso de concienciación. En la relación primaria entre madre e hija, muchas mujeres «oscillano tra vicinanza fusionale e fuga precipitosa al grido di «mai come lei» e [...] confondono il «con te» necessario al mantenimento di un' origine condivisa con un «come te» imprigionante e mortifero per l'inconscietà di chi lo abita e per le concrezioni culturali e simboliche che si sono formate nel corso della storia» (Rossi Doria, en Chemotti, 2009: 14' ${ }^{25}$. En su estudio acerca de la subjetivación femenina en la literatura, Biruté Ciplijauskaité (2004) clasifica las relaciones especulares madre-hija en tres categorías: el espejo positivo cuando, en la relación madre-hija la hija acepta, no sin cierta resignación, continuar con la línea de sus antepasadas y adopta un rol más pasivo aunque con posibilidad de atravesar un proceso de concienciación; el espejo negativo, que supone el rechazo por parte de la hija al verse reflejada en la madre o, en ocasiones, es la figura maternal la que reniega de la hija huyendo del rol materno y/o negándose a transmitir las desdichas propias del sexo femenino; y, por último, el espejo sin marco, donde la relación madre-hija se trata de manera sincrónica y se prioriza el enfoque de la experiencia maternal en sí misma.

En la novela en cuestión aparecen los tres espejos propuestos por Ciplijauskaité para enmarcar las relaciones madre e hija. Sin embargo, en estas relaciones suelen abundar los aspectos negativos y el rechazo hacia la otra figura femenina. Stiliana Milkova (2013) va más allá y utiliza el término «disgust», repugnancia, para referirse a dos puntos clave: los vínculos maternos-filiales y a la dimensión de la maternidad en su totalidad. Tomando como punto de partida este último, Olga experimenta un rechazo hacia su propio cuerpo tras haber experimentado la maternidad. Imagina el cuerpo joven de Carla, su delicada piel, sus senos firmes y, en definitiva, piensa en un cuerpo que aún mantiene su pureza. Para Olga, la maternidad es un lastre que tiene repercusiones directas en el cuerpo de la mujer: un desgaste físico y psicológico. La madre cede de su tiempo pero también de su propio espacio corpóreo que se ve obligada a sacrificar para dar vida a los hijos. Olga recuerda cuando sus hijos eran todavía pequeños y alude a una característica que le repugna: la emanación de un «malodore di mamma» (GA: 101). La protagonista rememora los momentos de la crianza inicial de los hijos y siente repulsión por el hecho de amamantar del mismo modo que hacen los animales o manchar su cuerpo con grumos o vómitos: «Scrivevo [...] come mi sentivo: un bolo fatto di materia viva che amalgamava e ammorbidiva continuamente la sua sostanza vivente per permettere a due sanguisughe voraci di nutrirsi lasciandomi addosso l'odore e il sapore dei loro succhi gastrici [...] Per quanto mi lavassi, quel malodore di mamma non se ne andava» $(G A: 101)^{26}$.

25 «oscilan entre la cercanía de la fusión y la fuga impetuosa al grito de «nunca como ella» y [...] confunden el «contigo» necesario para mantener un origen compartido con un «como tú» encarcelador y mortífero para la inconciencia de quien lo habita y para las concreciones culturales y simbólicas que se han formado a lo largo de la historia».

26 «Escribía [...] cómo me sentía: un bolo alimenticio hecho de materia viva que amalgamaba y reblandecía continuamente su sustancia viviente para permitir a dos voraces sanguijuelas alimentarse dejándome impregnado el olor y el sabor de sus jugos gástricos [...] Por más que me lavara, ese mal olor de madre no se cancelaba». 
Olga percibe la maternidad y la femineidad como dos polos opuestos; los hijos destruyen el cuerpo de la madre y aniquilan al sujeto privándole de lo femenino y convirtiendo su cuerpo en el «cuerpo de un incesto» (GA: 102). La maternidad se transforma en un sinónimo de sacrificio negativo, un dolor corporal y una humillación que concluirán con la muerte del sujeto femenino. Olga se define como «la madre da violare, non un'amante» (Ibídem), una mujer que ha perdido su cualidad de ser sexual y sexuado sacrificando su cuerpo por la maternidad. Ferrante hace referencia a esa dicotomía que se crea entre madre/mujer y reflexiona acerca de la pérdida de la condición física de la madre, argumentando que:

Il pensiero di figli e figlie, quando pensa il corpo a cui la parola dovrebbe rimandare, non riesce a dargli le forme che gli spettano se non con repulsione. Non ci riescono nemmeno le sarte delle madri, che pure sono femmine, figlie, madri. Esse anzi, per abitudine, in modo irriflessivo, tagliano addosso alla madre panni che cancellano la donna, come se la seconda fosse una lebbra per la prima. Lo fanno e così gli anni delle madri si trasformano in un mistero senza importanza, e la vecchiezza diventa la loro unica età $(L F: 16)^{27}$.

Olga reflexiona acerca de la maternidad y siente la abyección de su cuerpo, entendiendo el concepto kristevano de lo abyecto como «algo rechazado del que uno no se separa, del que uno no se protege de la misma manera que de un objeto. Extrañeza imaginaria y amenaza real, nos llama y termina por sumergirnos» (Kristeva, 1988: 11). Kristeva sostiene que lo que vuelve abyecto son los elementos que trastornan «una identidad, un sistema, un orden» (Íbidem). Olga experimenta la abyección física, tangible, a través de los residuos de comida que sus hijos le dejan sobre el cuerpo, y en un plano psicoanalítico, la protagonista adolece de una "pérdida inaugural fundante de su propio ser» (Kristeva, 1988: 12). Según la estudiosa, la maternidad es una experiencia melancólica «en la que la frustración y la hostilidad estancadas se vuelcan sobre el cuerpo de la madre, y por lo tanto, sobre el hijo» (Hidalgo Xirinachs \& Chacón Echeverría, 2001: 38).

El vínculo que mantiene Olga con su hija Ilaria de tan solo 7 años es un ejemplo de la proyección de hostilidad y frustración existente entre madre e hija. Su relación se caracteriza por los continuos enfrentamientos y la indiferencia que una siente por el sufrimiento de la otra. No obstante, a pesar de la repugnancia que siente cuando reflexiona acerca de la maternidad y el sentimiento hostil hacia Ilaria, será esta quien le ayude a retomar el control sobre su cuerpo y reconocerse en su totalidad. El punto de inflexión en su relación llega cuando Ilaria ve a la madre maquillada y siente una sincera admiración hacía la imagen materna, tras observar durante un largo tiempo el visible abandono físico de la madre. La imagen positiva de la madre redunda directa-

27 «El pensamiento de los hijos e hijas, cuando piensa en el cuerpo a cuya palabra debería remitir, non logra darle la forma que se esperan si no con repulsión. No pueden tampoco las sastras de las madres, que son también mujeres, hijas, madres. Esas, por costumbre, de forma irreflexiva, cortan sobre la madre las telas que cancelan a la mujer, como si la segunda fuera una enfermedad para la primera. Lo hacen y así los años de las madres se transforman en un misterio sin importancia, y es la vejez la que se convierte en su única edad». 
mente en la hija, quien no duda en seguir sus pasos y trata de imitarla en su forma de maquillarse y de vestirse. Lejos de admirarla, la imagen de la niña horroriza tanto a Olga que optará por desmaquillarla y desmaquillarse a sí misma, tratando de buscar desesperadamente una realidad con la que reconocerse y desde la que reconocer su entorno a través de una imagen pura, con el rostro desvelado ${ }^{28}$ : « Realtà, realtà, senza fard. Avevo bisogno di questo, per ora, se volevo salvarmi, salvare i miei figli, il cane» $(G A: 136)^{29}$. Olga siente repulsión hacia su hija, un sentimiento que aumenta no solo al ver a Ilaria maquillada sino que, en un intento de agradar a la madre, la niña afirma: «siamo identiche» (Ibídem) ${ }^{30}$. La afirmación de Ilaria tiene dos consecuencias inmediatas en Olga: en primer lugar percibe que llaria, viendo a la madre fuera de control tras el abandono, trata de aprovecharse de su debilidad para ganarle terreno y ocupar su lugar, algo que le obligará a actuar rápido para controlar a la hija. En segundo lugar, debido al momento de confusión y reconstrucción del "yo» en el que se encuentra, Olga se siente incapaz de ser un modelo de identificación para la hija puesto que todavía tiene que reconocerse a sí misma y recomponer una identidad fragmentada: «Che cosa significava siamo identiche, in quel momento avevo bisogno di essere identica solo a me stessa» $(G A: 135)^{31}$. Tras pronunciar estas palabras, Olga advierte que Ilaria no solo ha despertado un sentimiento negativo en ella sino que, paradójicamente, ha producido también una reacción positiva ya que la obliga a ver la realidad, ayudándola a distinguir entre la apariencia y el ser, la imagen e la imago de sí misma: «Questa era la realtà che stavo per scoprire, dietro l'apparenza di tanti anni. Non ero già più io, ero un'altra, come avevo temuto fin dal risveglio, come temevo chissà da quando. Ormai ogni resistenza era inutile, mi ero persa proprio mentre mi impegnavo con tutte le mie forze per non perdermi [...]» (Ibídem) ${ }^{32}$.

Tras desmaquillar a la niña, Olga decide emprender su recuperación apoyándose en su hija. Para ello, le da un abrecartas y le pide que lo utilice sobre su cuerpo cada vez que vea a la madre absorta en sus pensamientos. La idea de utilizar a la hija para salvarse y aferrarse a la vida implica una previa aceptación del amor hostil que siente Ilaria por la madre y juntas superarán el abismo: «Insieme- la madre e la figlia- affermeranno il diritto alla vita fuori, fuori dal modelo delle donne spezzate» $(L F: 79)^{33}$. La

28 La estudiosa Biruté Ciplijauskaité, haciendo referencia a las teorías del psicoanálisis, habla de la existencia del "yo» y argumenta que "para llegar a existir auténticamente como individuo es imprescindible, dice [Jung], despojarse de la máscara. A la concienciación, que debería ser la meta de todo ser pensante, se llega a través de la sensación de ser diferente» (1988: 87). Olga quiere distanciarse/diferenciarse de su propia proyección, una imagen oculta tras artificios, e iniciar su proceso de concienciación para llegar a situarse en una nueva realidad.

29 «Realidad, realidad, sin maquillaje. Necesitaba eso si quería salvarme y salvar a mis hijos, al perro».

30 «Somos idénticas».

31 «Qué significaba somos idénticas, en ese momento solo sentía la necesidad de ser idéntica a mí misma».

32 «Esta era la realidad que iba a descubrir, detrás de la apariencia de hace tantos años. Ya no era más yo misma, yo era otra, como temía desde que me desperté, como temía desde hace quién sabe cuánto. Ahora ya cualquier resistencia era inútil, me había perdido mientras me esforzaba con todas mis fuerzas para no perderme ...».

33 «Juntas -la madre y la hija- afirmarán el derecho a la vida lejos, lejos del modelo de las mujeres fragmentadas». 
relación de Olga e Ilaria, por tanto, se mueve en una continua contradicción: la madre permite que la hija le dañe utilizando un objeto punzante contra su cuerpo, dejando salir los sentimientos negativos contra ella pero, a su vez, la hostilidad de la niña le servirá para recordarle la necesidad de seguir viva, de avanzar: «hazme daño, usa tus malos sentimientos, pero recuérdame la necesidad de vivir» ${ }^{34}(L F: 114)$. El control físico y emocional son dos componentes muy representativos de la personalidad de $\mathrm{Olga}^{35}$. A esta disciplina autoimpuesta Ferrante la llama «sorveglianza», un concepto que define como « [...] una disposizione affettiva di tutto il corpo, un suo distendersi e germogliare sopra e intorno» $(L F: 113)^{36}$. Mientras que en un momento inicial Olga autoejerce una vigilancia psicológica que Ferrante tilda de «masculina» por controlar los sentimientos y mostrarse poco impulsiva para resultar complaciente, al final de la novela esta se sirve de su hija para poner en práctica una vigilancia positiva que la escritora relaciona con el significado original de la palabra, es decir, la voluntad de «restare vigile, cioè, recuperare il desiderio di veglia» $(L F: 114)^{37}$. La «sorveglianza» a través de la que logra superar su crisis existencial está íntimamente ligada al dolor ${ }^{38}$, una relación que remite a la noción del panoptismo empleada por Michel Foucault en su obra Surveiller et punir (1975). Foucault afirma que las relaciones sociales de poder se sostienen por tres principios básicos: vigilar, controlar y corregir. Elena Ferrante toma esos tres pilares básicos de la «sorveglianza» y los aplica al ámbito familiar, responsabilizando a Ilaria de tener el control sobre la disciplina materna y convertir así el cuerpo rebelde en un cuerpo sometido, transformado y que, posteriormente, resultará mejorado.

\subsection{Olga y los fantasmas de la «madre»}

Una vez superado el traumático episodio del maquillaje y el abrecartas, Olga logra reconducir la relación con su hija asumiendo la maternidad desde otra perspectiva. Siguiendo el estudio de Saveria Chemotti, las mujeres logran liberarse de la maternidad como rol, tal y como se ha concebido histórica y socialmente, iniciando un conflicto con la propia maternidad y que comienza por afrontar el «fantasma» de la propia madre, un hecho que significa para las mujeres «... reinterpretare la propria differenza sessua-

34 «Fammi male, usa i tuoi cattivi sentimenti, ma ricordami il bisogno di vivere».

$35 \mathrm{Al}$ inicio de la novela, ésta se presenta como una persona serena y con un gran control sobre sus emociones. Sin embargo, en una lectura más profunda, su aparente moderación está estrechamente relacionada con una fuerte represión como consecuencia, en parte, de la educación recibida y de su entorno natal, factores que obstaculizarán la libre expresión de los sentimientos, mermados por los límites expresivos que se ha autoimpuesto para evitar dar una imagen alterada de sí misma: «Anche per tenere sotto controllo l'angoscia dei mutamenti mi ero definitivamente abituata ad aspettare con pazienza che ogni emozione implodesse e prendesse la via della voce pacata, custodita in gola per non dare spettacolo di me»«También para tener bajo control la angustia de los cambios me había definitivamente habituado a esperar con paciencia que cada emoción explotase y se llevase la voz serena, custodiada en la garganta para no dar un espectáculo de mi misma» (GA:11).

36 «... una disposición afectiva sobre todo el cuerpo, una distensión y germinación por encima y alrededor».

37 «permanecer vigilantes, recuperar ese deseo de viglia».

38 Anteriormente Olga, prescindiendo de la ayuda de Ilaria, decide clavarse una pinza en el brazo para tratar de controlar su cuerpo y evitar dejarse llevar por sus pensamientos paranoicos y alucinaciones. 
le, rompendo la continuità col modello materno codificato, per cercare nelle proprie madri la donna, rifiutando al contempo come figlie, il mimetismo cieco per instaurare una relazione di somiglianza nella differenza» (Chemotti, 2009: 14) ${ }^{39}$. Olga se enfrenta al doble fantasma de la madre, la real y la simbólica. Desde pequeña, la protagonista participaba de las conversaciones que su madre y otras mujeres mantenían mientras cosían. Las mujeres contaban historias de otras mujeres, de vidas truncadas, y emitían juicios marcados por la sociedad patriarcal en la que vivían. Olga tiene un recuerdo traumático de su infancia, de la vida en el Sur, concretamente de su ciudad, Nápoles, y decide alejarse de ese recuerdo emocional e intelectualmente.

Tras sufrir el abandono, la protagonista rememora una de las historias que su madre contaba acerca de una mujer que fue abandonada por su marido a quien todos llamaban la poverella: «La donna perse tutto, anche il nome (forse si chiamava Emilia), diventò per tutti «la poverella», cominciammo a parlarne chiamandola così» $(G A: 15)^{40}$. La mujer no pudo soportar el dolor y decidió ahogarse en las aguas de Capo Miseno, renunciando a su vida y a la dignidad que el marido le había arrebatado. La poverella es un personaje que encarna la angustia de una multitud de mujeres que vivían en una sociedad patriarcal y es, a su vez, una sombra negra que planea sobre Olga, quien tratará de no sucumbir al destino de la mujer: «Non fare come la poverella, non consumarti in lacrime. Evita di assomigliare alle donne in frantumi di un libro famoso della tua adolscenza» $(G A: 20)^{41}$.

La manera en la que Olga logrará superar los recuerdos negativos de su infancia es enfrentándose a ellos y aceptando un pasado que no necesariamente tiene que repercutir en el tiempo presente como un destino inevitable de todas las mujeres. Aceptando a la madre real y a la madre simbólica, Olga logra mantener una distancia emocional y comprende que aquellas mujeres se regían por los códigos de un orden simbólico falogocéntrico en el que el elemento femenino y maternal era marginado. La protagonista restablece un nuevo orden y, poco a poco, comienza a identificarse con ella misma, sin necesidad de verse reflejada en las madres, reconociendo la diferencia:

Leggevo e intanto mi sentivo al sicuro, non ero più come le signore di quelle pagine, non le sentivo come una voragine che mi risucchiava. Mi accorsi che avevo persino sepolto da qualche parte la moglie abbandonata della mia infanzia napoletana [...]. La poverella era diventata come una vecchia foto, passato impietrito, senza sangue (GA: 206-207) ${ }^{42}$.

39 «... reinterpretar la propia diferencia sexual, rompiendo la continuidad con el modelo materno codificado, para buscar en las propias madres la mujer, rechazando al mismo tiempo como hijas, el mimetismo ciego para instaurar una relación de semejanza en la diferencia».

40 «La mujer perdió todo, también el nombre (quizá se llamaba Emilia), fue para todos «la poverella», comenzamos a hablar y a llamarla así».

41 «No hagas como la poverella, no te consumes en lágrimas. Evita parecerte a las mujeres hechas añicos de un libro famoso de tu adolescencia».

42 «Leía y mientras tanto me sentía segura, no era ya como las señoritas de aquellas páginas, no las sentía como una vorágine que me chupaba. Me di cuenta de que había además sepultado por alguna parte a la mujer abandonada de mi infancia napolitana [...] La poverella se había convertido en una vieja foto, pasado petrificado, sin sangre». 


\section{Conclusión}

A lo largo del siglo XX, las escritoras han subvertido el canon literario y han propuesto nuevos imaginarios femeninos desde los que las mujeres reflexionaban sobre sí mismas, sobre la memoria y sus experiencias en el mundo a través de la propia subjetividad. En este imaginario, la maternidad y las relaciones materno-filiales han sido argumentos centrales para comprender una de las facetas que más ha condicionado la vida de las mujeres en la historia por su matiz biológico principalmente:

... le scrittrici raccontano i rapporti intensi e conflittuali che si intersecano con la loro storia di donne e la loro identità individuale muovendosi sempre meno dentro i canoni della cultura patriarcale in cui scompare la sessualità femminile e la madre è solo genitrice, più vicina all'animalità che alla femminilità, essendo legata solo alla riproduzione e al corpo (Chemotti, 2009: 22) ${ }^{43}$.

Representar la maternidad en la literatura, por lo tanto, supone proyectar las percepciones y las actitudes femeninas de la realidad, apartando los códigos literarios androcéntricos para darle mayor visibilidad a la mujer.

Como se ha visto, una de las escritoras que ha analizado esas relaciones «intensas y conflictuales» de la madre con los hijos y con su propia identidad ha sido Elena Ferrante. La escritora opta por reconstruir la vida de las mujeres desde la subjetividad de sus vivencias, valorando las experiencias de las mujeres en su totalidad con matices que enriquecen a los personajes, como la visión de la maternidad. En una narrativa compleja por la temática existencial, el personaje de Olga representa, en un contexto similar a la poverella aunque desde una perspectiva diversa, la angustia de las mujeres que viven en la cultura patriarcal y son abandonadas, cayendo sobre ellas el peso de un sistema de valores en el que no se ven ya reflejadas. Olga sucumbe gradualmente a las consecuencias del abandono y lo proyecta a través de la sexualidad y la dicotomía que experimenta con la maternidad, pero logrará recomponerse con ayuda de varios apoyos, entre ellos, el de su hija. Enfrentándose a su temor/repulsión por la maternidad y a las relaciones con la madre real y simbólica, la protagonista logrará recomponer facetas de sí misma y asimilar su relación con Ilaria, aceptando la maternidad desde una perspectiva renovada que desestabiliza la idea masculina de la madre.

\section{REFERENCIAS Y BIBLIOGRAFÍA}

Aleramo, Sibilla (1906) Una donna. Milano: Feltrinelli, 2011.

Ávila EspadA, Alejandro; Rojí MenchacA, Begoña; SAúl Gutierrez, Luis Ángel (2014) Introducción a los Tratamientos Psicodinámicos. Madrid: UNED.

$43 \ll \ldots$ las escritoras cuentan las relaciones intensas y conflictivas que se entrecruzan con su propia historia de mujeres y su propia identidad individual moviéndose siempre menos dentro de los cánones de la cultura patriarcal en los que desaparece la sexualidad femenina y la madre es solo progenitora, más cercana a la animalidad que a la feminidad, quedando vinculada solo a la reproducción y al cuerpo». 
BIASETTI, Giada (2009) El poder subversivo de la nueva novela histórica femenina sobre la conquista y la colonización: la centralización de la periferia. Gainesville: Universidad de Florida.

Blelloch, Paola (1987) Quel mondo di guanti e delle stoffe: profili di scrittrici italiane del '900. Verona: Essedue.

Bobes Naves, María del Carmen (1996) «Novela Histórica Femenina», La novela histórica a finales del siglo XX. Madrid: Visor Libros, pp. 39-54.

Chemotтi, Saveria (2009) L'inchiostro bianco. Madri e figlie nella narrativa italiana contemporanea. Padova: Il Poligrafo.

CiplijausKaité, Biruté (1988) La novela femenina contemporánea (1970-1985). Barcelona: Anthropos.

- (2004) La construcción del yo femenino en la literatura. Cádiz: Universidad de Cádiz.

Conti, Eleonora (2015) «Abiti, madri e figlie ne L'Amore molesto di Elena Ferrante». En Lettera Zero, núm. 1, pp. 103-113.

De Giovanni, Neria (2003) E dicono che siamo poche... Scrittrici italiane dell'ultimo Novecento. Roma: Quaderni Rosa.

FERRANTE, Elena (2002) I giorni dell'abbandono. Napoli: Edizioni e/o.

- (2003): La Frantumaglia. Napoli: Edizioni e/o.

FoucAult, Michel (1975): Surveiller et punir. Paris: Gallimard.

Herrero Gil, Marta (2014) «Maternidad y Literatura. Introducción», Centro virtual Cervantes. 27 de Junio de 2014. http://cvc.cervantes.es/el_rinconete/anteriores/junio_14/27062014_01.htm

Hidalgo Xirinachs, Roxana \& Chacón Echeverría, Laura (2001) Cuando la feminidad se trastoca en el espejo de la maternidad. San José: Universidad de Costa Rica.

Kristeva, Julia (1989) Poderes de la perversión: ensayo sobre Louis-Ferdinand Céline. México: Siglo XXI.

KüHL, Sara (2016) «The Angel in the House and Fallen Women: Assigning Women their Places in Victorian Society», Open Educational Resources, University of Oxford. 14 de Enero de 2016. http://open.conted.ox.ac.uk/resources/documents/angelhouse-and-fallen-women-assigning-women-their-places-victorian-society

Massimi, Fabiano (ed.) (2010) Di mamma ce n'è una sola. Racconti sull'amore più grande. Milano: Einaudi.

MilkovA, Stiliana (2013) «Mothers, Daughters, Dolls: On Disgust in Elena Ferrante's La figlia oscura», Italian Culture, XXXI (2), pp. 91- 109.

Moreno, Hortensia (1994) «Crítica literaria feminista», En Debate feminista.Vol. 9, pp. 107-112.

Peppino Barale, Ana María (2012) «Lectura feminista y canon androcéntrico. Notas para una reflexión incluyente», En Multidisciplin@ Revista electrónica de la Facultad de Estudios Superiores Acatlán, núm. 1, pp. 116- 120.

Rossi DoriA, Anna (1993) «Memoria, storia e politica delle donne» en Capobianco, Laura (ed.) Donne tra memoria e storia. Napoli: Liguori Editore.

Santoro, Anna (1997) Il Novecento: Antologia di scrittrici italiane del primo ventennio. Roma: Bulzoni Editore.

Sgorlon, Carlo (1988) Invito alla lettura di Elsa Morante. Milsno: Mursia. 
STINGHI, Chiara (2005) «La comparsa della donna nella scrittura», Letteratour, 26 de Octubre de 2005. http:/ / www.letteratour.it/tesine/A06donne01.asp Sullà, Enric (1998) El canon literario. Madrid: Arco/Libros.

ZANCAN, Marina (1998) Il doppio itinerario della scrittura. La donna nella tradizione letteraria italiana. Torino: Einaudi.

Recibido el 3 de marzo de 2016 Aceptado el 7 de noviembre de 2017 BIBLID [1132-8231 (2017): 47-63] 